\title{
Que va penser notre descendance de nous?
}

\author{
Hansjakob Müller \\ Prof. ém. en génétique médicale, Université de Bâle
}

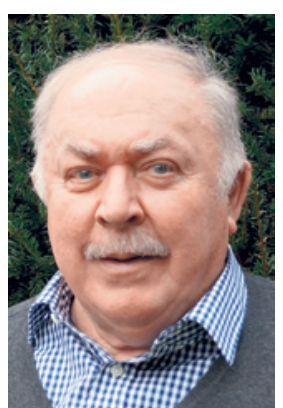

Dans la culture germanique notamment, les activités et déclarations des spécialistes de la génétique humaine et médicale sont suivies de façon très critique. Ainsi, à l'instar des domini canes ou des journalistes d'opinion, les historiens et historiennes recherchent parmi les pionniers et pionnières de notre discipline les éventuels écarts par rapport à une bonne attitude médicale telle qu'on l'entend aujourd'hui, afin de les discréditer dans leurs publications.

Entre les deux Guerres mondiales, plusieurs médecins suisses, parmi lesquels Ernst Hanhart (1891-1973), sont arrivés à des conclusions décisives sur les maladies héréditaires, qui sont la conséquence de l'implexe dans la population des étroites vallées des régions alpines, avec les différentes religions et langues locales. Ils ont employé l'anamnèse familiale, soigneusement établie, et son analyse d'après les lois de Mendel, des procédés de la recherche en génétique humaine qui sont encore aujourd'hui actuels et en aucun cas uniquement liés à l'époque nazie [1]. La génétique humaine et ses disciplines proches, comme les neurosciences, ayant fait d'énormes progrès en Allemagne après la Première Guerre mondiale, la Suisse s'est inspirée de cet état de la science, en évitant toutefois les abus inhumains de l'eugénisme et de l'hygiène raciale du Troisième Reich.

La médecine de la deuxième moitié du siècle dernier a été marquée par les mesures de prévention rendues possibles grâce à la génétique humaine, comme l’introduction du diagnostic prénatal. On voulait alors instaurer la discipline de la génétique médicale dans les facultés de médecine, soulignant son utilité à la limitation des coûts de la santé. A une époque où les professionnelles et professionnels des laboratoires d'analyse chromosomique notamment représentaient la génétique médicale en Suisse, Hans Moser (1935-2005), pédiatre averti et spécialiste des maladies neuromusculaires, attirait l'attention sur des aspects encore actuels aujourd'hui du conseil génétique des personnes concernées et de leurs proches. Les reproches d'une historienne [2] selon laquelle le médecin aurait adopté une relation paternaliste avec sa patientèle et fait preuve d'une croyance et d'une candeur technologiques face aux risques d'eugénisme ne sont pas suffisamment fondés et constituent ainsi des allégations factuellement incorrectes.

Le but ici n'est pas de considérer tous les actes et opinions exprimées par les générations précédentes à l'aune d'un contexte historique spécifique pour pouvoir les justifier. Il est toujours difficile a posteriori de comprendre et d'interpréter avec justesse des concepts donnés, les intérêts de la recherche de l'époque, les technologies alors disponibles, les liens sociaux, le contexte social ainsi que les interactions avec la politique et l'opinion publique.

\section{Les normes en vigueur peuvent très rapide- ment changer.}

Mon activité professionnelle m'a permis de saisir à quelle vitesse les normes en vigueur changent en fonction des époques. Si nous voulons laisser à la postérité une image représentative de l'histoire de la génétique médicale, nous devrions, en tant que témoins de notre temps, consigner les conditions qui prévalent à chaque époque pour pouvoir ensuite les évaluer avec l'aide de spécialistes des différentes disciplines. L'examen des comportements ne demande une coopération interdisciplinaire pas qu'aux historiennes et historiens, mais à nous aussi. On peut aujourd'hui pour ce faire consulter les positions des différentes instances de bioéthique. Nous ne saurons pas comment les prochaines générations évalueront, avec le whole genome sequencing et le CRISPR gene-editing, nos actes en ce début de siècle. Mais sommes-nous de «meilleures personnes» que nos ancêtres? Sûrement pas!

\section{Références}

1 Germann P. Vergessene Kooperationen. Bull Med Suisses. 2017;98(9):262-5.

2 Argast R. Un eugénisme ingénu? Hans Moser et le renouvellement du conseil génétique en Suisse, 1974-1980. Transverse: Revue d'histoire. 2011;18:85-103. 